\title{
Algorithmic Component of the New Statistical Quality Control Software Module
}

\author{
Olesya Golubeva ${ }^{1, *}$, Alina Pogorelova ${ }^{1}$, and Viktor Mirnyy ${ }^{1}$ \\ ${ }^{1}$ Don State Technical University, 1, Gagarin Square, 344003, Rostov-on-Don, Russia
}

\begin{abstract}
Great development of information technologies largely determines the content of modern management, providing managers abilities for automatical data collection and processing, making decisions based on the use of a wide range of application software for various purposes. The use of quality management methods and tools is an important condition for product competitiveness. The possibility of using the software module as part of the developed information system is proposed. The article gprovides detailed description of statistical software module development for the purpose of product quality control. It is concluded that it is expedient and necessary to introduce this development into production.
\end{abstract}

\section{Introduction}

At present the issue of quality and automation improvement in production of Shoe enterprises is acute in the world. [1]

In order to improve the quality of manufactured products, more flexible configuration of the production process by timely tracking of defects in manufactured products at each stage of production, use of modern technologies in production planning, such as the Ishikawa diagram, the software module was developed as part of the information system, which is designed to solve many issues of production process quality management through automatic data processing and using various quality tools.

The program for calculating statistical indicator, evaluating the quality of goods and services "Expert" was developed in January 2020 by the team of employees and students of the Don State Technical University by Golubeva Olesya Anatolyevna, Shemerey Georgy Ivanovitch, Nikolaeva Nadezhda Aleksandrovna, Fomichenko Yuliya Aleksandrovna.

One of the possible areas for the program application is its use for performing work related to the study and development of statistics and quality assessment methods for production process. This program is also intended for implementation in the information system for use in enterprises in order to improve the quality of production process preparation.

\section{Materials and Methods}

\footnotetext{
*Corresponding author: 1354565@mail.ru
} 
The developed software is based on the functionality for automatic analysis and processing of input data from operators desktop computers at each production process stage. There can be both identification with elimination of problem areas of production, and application of new production methods of quality management with flexible adjustment of the production process and its timely adjustment. [2]

It has become possible by introducing statistical quality control methods: Shewhart $\mathrm{X}$ and $\mathrm{R}$ control maps, Pareto diagrams, control maps of the number and proportions of discrepancies, control maps of the number of discrepancies, and scatter diagrams in the developed software.

The production planning process has become more flexible by expanding the functionality of the created software with the ability to build Ishikawa diagrams.One of the advantages of the developed software is the ability to introduce it in a larger information system that exisits in the enterprise.

\section{Research Results}

At the stage of preparation for writing the source code of the software, the production processes were analyzed. Based on these data, methods of statistical management of the production process were selected for implementation in the developed information system.

The developed information system, designed for use on desktop computers, has extensive functionality for analyzing statistical data with input of initial information by manual and automatic methods.

In this article we will look at the algorithmic work plan of such quality tools as Shewhart Control maps X and R, Control maps of the number of inconsistencies, Control maps of the number and proportions of inconsistencies.

For example overview of the quality tool "Control charts X and R" in the developed software tool is presented in the figure 1 .

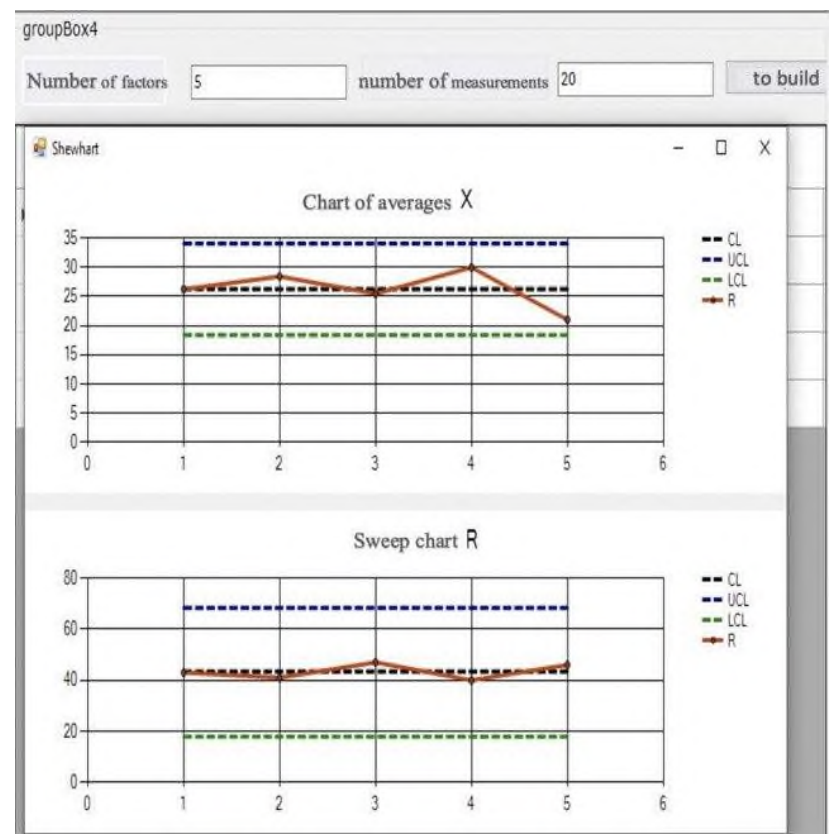

Fig. 1. Overview of the quality tool "Control charts $X$ and R" in the developed software tool. 
The Control cards are quality control statistical tool which is a graphical representation of output information according to which you can visually track at what specific time in the enterprise there were or exist deviations in goods or services production in real time. [3]

In the developed software module, the Shewhart control cards X and $\mathrm{R}$ work according to the following algorithm:

- initializes the initial state and configures the monitoring process;

- planned observation period;

- a sample is being prepared for inspection;

- measurements are performed according to the measurement method;

- average values of the parameter are calculated. Calculations are made using the formula:

$$
X_{c p}=\frac{\sum_{i=1}^{n} X_{i}}{n}
$$

where $\mathbf{n}$ is the total number of parameters, $\mathbf{i}$ is the current index of the parameter and

$\mathrm{Xn}$ is the parameter at the current iteration;

- calculation of the average span value:

$$
R_{c p}=\frac{\sum_{i=2}^{n} R_{i}}{n-1}
$$

where $\mathbf{n}$ is the total number of parameters, $\mathbf{i}$ is the current index of the parameter and $\mathrm{Ri}$ is the parameter at the current iteration;

- checking the data completeness and the need for additional tests for precision;

- checking the calculations correctness;

- checking control card violations;

- checking indicators evaluation;

- evaluationg indicators;

- checking statistical reachability;

- checking assessment violations;

- the measurement procedure is suspended;

- the current calculation process is being completed.

P-map is the control map of the share of defects, which is used when it is necessary to control the quality indicator, represented by the shares of defective products on a quality basis. This map is used when the volume of the sample under study changes. This takes into account the fact that the upper bounds can also be variable. With a quantitative quality attribute equal to two, it is customary to calculate the boundaries of statistical stability, i.e. 3 Sigma from the binomial distribution. If such a quantitative quality attribute is equal to or greater than three, then a polynomial distribution is used instead of a binomial distribution [4].

The $\mathrm{P}$ - map of defective products is a single graph that shows the following data:

- calculated values of defect levels;

- average defect levels;

- regulatory boundaries.

The P-map is built in the developed software module according to the following scenario:

- the initial state and configures the monitoring process is initialized;

- observation period is planned;

- a sample for inspection is prepared;

- initial data is collected for further processing according to the following principle: products are classified as proper or unsatisfactory depending on the regulatory documents. 
Then the existing sample is divided into subgroups with the condition that each of them will contain defective products in the amount from 1 to 5 . Another condition is that there are from 20 to 25 of such subgroups in the end after the above manipulations.

- checking the correctness of the input information and its belonging to the process under study;

- determining the proportion of defective products in each of the samples using the formula:

$$
\mathrm{p}_{\mathrm{i}}=\frac{\mathrm{D}_{\mathrm{i}}}{\mathrm{n}_{\mathrm{i}}} * 100 \%
$$

where $\mathrm{Di}$ isthe number of defective products that were detected in the i-th batch of products, ni - the number of units in the aggregate from the $\mathrm{i}$-th batch;

-the percentage of defective products from each $\mathrm{i}$-th batch is calculated using the formula:

$$
\mathrm{p}_{\mathrm{i}}=\frac{\mathrm{D}_{\mathrm{i}}}{\mathrm{n}_{\mathrm{i}}} \times 100 \%
$$

where $\mathrm{Di}$ is the number of defective products that were detected in the $\mathrm{i}$-th batch of products, ni is the number of units in the aggregate from the i-th batch;

- the average level of product defect indicators is calculated using the formula:

$$
\bar{p}=\frac{\sum_{i=1}^{k} \mathrm{D}_{\mathrm{i}}}{\mathrm{n} \times \mathrm{k}}
$$

where $\mathrm{Di}$ isthe number of defective products that were detected in the $\mathrm{i}$-th batch of products, ni is the number of units in the aggregate from the $\mathrm{i}$-th batch; $\mathrm{k}$ is the total number of batches;

- the upper permissible control limit of the control map is calculated using the formulas:

$$
\mathrm{UCL}_{p}=\overline{\mathrm{p}}+3 \sqrt{\frac{\overline{\mathrm{p}}(1-\overline{\mathrm{p}})}{\mathrm{n}}}
$$

where $\mathrm{n}$ is the total set of the subgroup, $\overline{\mathrm{p}}$ is the indicator of the average defect of the product from the batch;

- the lower acceptable control border of the control map is calculated using the formulas:

$$
L C L_{p}=\overline{\mathrm{p}}-3 \sqrt{\frac{\overline{\mathrm{p}}(1-\overline{\mathrm{p}})}{\mathrm{n}}}
$$

where $\mathrm{n}$ is the total set of the subgroup and $\overline{\mathrm{p}}$ is the indicator of the average defect of the product from the batch;

Note: the lower control limit of the control card is not calculated if it is negative;

- the average allowable control border of the control map is calculated using the formulas:

$$
\mathrm{CL}_{p}=\overline{\mathrm{p}}
$$

where $\mathrm{n}$ is the total population of the subgroup;

- control lines and all received data on the control map are drawn;

- indicators are evaluated;

- statistical reachability is checked;

- checking for violations of the assessment is carried out; 
- the measurement procedure is suspended;

- the current calculation process is being completed.

Control NP-maps are maps that are used for quality control only when it is known that the controlled sample is always of fixed size. [5]

The map-NP of defective products is a single graph that shows the following data:

- calculated values of defect levels;

- average defect levels;

- regulatory boundaries.

Duriong the control np-map construction should be taken into account that the upper bounds can be also variables. With a quantitative quality attribute, as well as when constructing a control p-map equal two, it is customary to calculate the boundaries of statistical stability, i.e. 3 Sigma, from the binomial distribution. If such a quantitative quality attribute is equal to or greater than three, then a polynomial distribution is used instead of a binomial distribution. [6-8]

To build the number of mismatches NP-map the following operations are performed in the program module:

- the initial state is initialized and monitoring process is configured;

- observation period is planned;

- a sample for inspection is being prepared ;

- initial data are collected for further processing according to the following principle: products are classified as good or not, depending on the regulatory documents. Then the resulting sample is divided into subgroups with the condition that each of them will contain defective products in the amount from 1 to 5 . Another condition is that after the above manipulations there are from 20 to 25 of such subgroups in the end.

- checking the correctness of the input information and its belonging to the process under study;

- the average number of defective products in each sample is determined using the formula:

$$
\overline{n p}=\frac{\sum_{i=1}^{k} D}{\mathrm{k}}
$$

where $\mathrm{D}$ is the total number of units in a subgroup, and $\mathrm{k}$ is the total number of such subgroups;

- the upper permissible control limit of the control map is calculated using the formulas:

$$
\mathrm{UCL}_{n p}=\overline{\mathrm{np}}+3 \sqrt{\overline{n p}(1-\bar{p})}
$$

where $n p^{-}$is the average number of defective products and $\bar{p}$ is an indicator of the average defect of products from the batch;

- the lower acceptable control border of the control map is calculated using the formulas:

$$
\mathrm{LCL}_{n p}=\overline{\mathrm{np}}-3 \sqrt{\overline{n p}(1-\bar{p})}
$$

where $n p^{-}$isthe average number of defective products and $\overline{\mathrm{p}}$ is an indicator of the average defect of products from the batch;

Note: the lower control limit of the control card is not calculated if its value is negative; - the average allowable control border of the control map is calculated using the formulas:

$$
\mathrm{CL}_{n p}=\overline{\mathrm{np}}
$$


where $n p^{-}$is the average number of defective products;

- draw control lines and all received data on the control map;

- indicators are evaluated;

- statistical reachability is checked;

- checking for violations of the assessment is carried out;

- the measurement procedure is suspended;

- the current calculation process is being completed.

Applying control maps of the number and proportion of discrepancies in the developed statistical software module the Shoe company will achieve more detailed tracking of products that were subject to defects in the production process. [9]

In contrast to the $\mathrm{P}$ and $\mathrm{nP}$ control map, the control c-map of the number of inconsistencies is used in the case of monitoring the observed parameters when there may be several inconsistencies in the observed object at the same time.

The control u-map of the number of nonconformities per unit of production is used for tracking and managing processes based on samples from the evaluation of the proportion of defects by means of the partial number of identified nonconformities and the number of quality and non-defective products. [10,11]

Existing control cards according to the calculation and construction algorithm in the developed software module are very similar and have the following form:

- the initial state and configures the monitoring processin is itialized;

- observation period is planned ;

- a sample is being prepared for inspection;

- initial data is collected for further processing according to the following principle: products are classified as satisfactory or unsatisfactory depending on the regulatory documents. Then the resulting sample is divided into subgroups with the condition that each of them will contain defective products in the amount from 1 to 5 . Another condition is that after the above manipulations there are from 20 to 25 of such subgroups in the end.

- correctness of the input information and its belonging to the study process is checked;

- the upper acceptable control border of the control map is calculated;

- the lower acceptable control border of the control map is calculated;

Note: the lower control limit of the control card is not calculated if its value is negative;

- the average allowable control border of the control map is calculated;

- control lines and all received data on the control map are drawn;

- indicators are evaluated;

- statistical reachability is checked;

- checking of assessment violations is carried out;

- the measurement procedure is suspended;

- the current calculation process is being completed.

The algorithms differ only in the principles of finding control boundaries of regulation with the middle line and the rule of finding the average number of discrepancies for the $\mathrm{C}$ card with the rule of finding the average number of discrepancies per unit of production for the u-card. [12]

For the control C-card the average number of inconsistencies is calculated using the formula:

$$
\bar{c}=\frac{\sum_{i=1}^{k} c_{i}}{k}
$$

where $\overline{\mathrm{c}}$ is the number of inconsistencies in each subgroup and $\mathrm{k}$ is the number of subgroups; 
The upper acceptable control boundary of the control C-map is calculated using the formula:

$$
U C L_{c}=\bar{c}+3 \sqrt{\bar{c}}
$$

where $\mathrm{c}^{-}$is the average number of sample inconsistencies.

The average allowable control boundary of the control C-map is calculated using the formula:

$$
C L_{c}=\bar{c}
$$

where $\overline{\mathrm{c}}$ is the average number of sample inconsistencies.

The lower acceptable control boundary of the control C-map is calculated using the formula:

$$
L C L_{c}=\bar{c}-3 \sqrt{\bar{c}}
$$

where $\overline{\mathrm{c}}$ is the average number of sample inconsistencies.

For the control u-card the average number of nonconformities per unit of production is calculated using the formula:

$$
\bar{u}=\frac{\sum_{i=1}^{k} D}{k}
$$

where $\mathrm{D}$ is the total number of units in a subgroup and $\mathrm{k}$ is the total number of such subgroups.

The upper acceptable control boundary of the control C-map is calculated using the formula:

$$
U C L_{u}=\bar{u}+3 \sqrt{\frac{\bar{u}}{\bar{n}}}
$$

where $\bar{u}$ is the average number of defective products and $\bar{n}$ isthe average value of the sample.

The average allowable control boundary of the control C-map is calculated using the formula:

$$
C L_{c}=\bar{u}
$$

where $\bar{u}$ is the average number of defective products.

The lower acceptable control boundary of the control C-map is calculated using the formula:

$$
L C L_{u}=\bar{u}-3 \sqrt{\frac{\bar{u}}{\bar{n}}}
$$

where $\overline{\mathrm{u}}$ is the average number of defective products and $\overline{\mathrm{nis}}$ the average sample size.

\section{Discussions and Conclusions}


Thanks to its flexible and rich functionality the developed software can be implemented at any enterprise that produces finished products. [13-15] Thanks to the use of quality management tools, new methods of information processing and timely elimination the prevention of production inaccuracies are possible. This will significantly simplify and automate the quality management process within the enterprise. [16]

Number of the Certificate of the State Registration for the Developed Software Module RU 2020612932, Application Number 2020610998, Registration date 04.02.2020.

\section{References}

1. K. Linz, G. Muller-Stievens, A. Zimmerman, Radical change in Business Model, Adaptation and survival in a competitive environment (Alpina Publisher, 2019)

2. K.V. Rochev, Information Technology. Analysis and Design of Information Systems (2019)

3. A. Halim, Pengaruh Kompetensi dan Independensi Auditor Terhadap Kualitas Audit dengan Anggaran Waktu Audit dan Komitmen Profesional Sebagai Variabel Moderasi. Disertasi. Universitas Brawijaya (Malang, 2013)

4. O.L. Golitsina, I.I. Popov, N.V. Maksimov, Information Systems and Technologies. Tutorial (2019)

5. D.Y. Katalevskiy, A.Y. Ivanov, Modern Agrotechnologies, Economic and Legal and Regular Aspects (2018)

6. A.G. Skhirtladze, Technological Process Automation (2016)

7. I.F. Borodin, Automation of Technological Processes and Automatic Control Systems (2018)

8. L.A. Ginis, Statistical Methods of Quality Control and Management, Applied Software (2019)

9. A.K. Ershov, Quality Management (2017)

10. S.I. Solonin, Control Charts Methods (2014)

11. I.V. Maruseva, Modern Management, Classic and Applied Aspects (2018)

12. V.N. Kraev, Management Decision Making Methods (2014)

13. J.C. Choi, C. Kim, J. Mater. Process Technol. 110 (2013)

14. G. Colombo, D. Ferretti, U. Cugini, Proceedings of international symposium on advanced geometric modelling for engineering applications 2-15 (2014)

15. G. La Rocca, L. Krakers, M.J.L. van Tooren, Proceedings 9th symposium on multidisciplinary analysis and optimization 2-13 (2014)

16. A. Luximon,, Handbook of Footwear Design and Manufacture 64(5), 416 (2013) 